\title{
Cyclopamine sensitizes multiple myeloma cells to circularly permuted TRAIL-induced apoptosis
}

\author{
HUIJUAN WANG, CHUANYING GENG, HUIXING ZHOU, ZHIYAO ZHANG and WENMING CHEN
}

Department of Hematology, Beijing Chaoyang Hospital, Capital Medical University, Beijing 100020, P.R. China

Received July 27, 2020; Accepted January 27, 2021

DOI: $10.3892 / \mathrm{ol} .2021 .12556$

\begin{abstract}
Tumor necrosis factor related apoptosis inducing ligand (TRAIL) is a promising anti-myeloma drug prototype. The aim of the present study was to investigate the synergistic effects of cyclopamine and circularly permuted TRAIL (CPT) on the proliferation and apoptosis of multiple myeloma cells. The results showed that the inhibitory effects of cyclopamine on the proliferation of human myeloma RPMI-8226 and SKO-007 cells were weak. RPMI-8226 cells were sensitive to CPT; however, the proliferation of SKO-007 cells was not effectively inhibited by CPT. SKO-007 cells were thus considered resistant to cyclopamine and CPT and used for subsequent experiments. Treatment with a combination of cyclopamine and CPT significantly inhibited cell proliferation. Moreover, the $\mathrm{Q}$ value showed that cyclopamine combined with $\mathrm{CPT}$ could synergistically inhibit the proliferation of SKO-007 cells. Cyclopamine increased CPT-induced apoptosis in the SKO-007 cells and exhibited a synergistic induction of apoptosis when combined with CPT. Moreover, the combination of cyclopamine and CPT decreased the ratio of myeloma stem cells. Quantitative PCR showed that cyclopamine decreased the mRNA expression levels of GLI1/GLI2/GLI3 and increased the expression levels of death receptor 4 . In conclusion, the present study showed that a combination of cyclopamine and CPT exhibited synergistic effects on the inhibition of proliferation and induction of apoptosis in myeloma cells.
\end{abstract}

\section{Introduction}

Multiple myeloma (MM) is a cancer of the plasma cells, which presents as anemia, kidney function damage, bone disease and extramedullary plasmacytoma $(1,2)$. Novel drugs

Correspondence to: Dr Chuanying Geng or Dr Wenming Chen, Department of Hematology, Beijing Chaoyang Hospital, Capital Medical University, 8 Gongti South Road, Beijing 100020, P.R. China

E-mail: gengcy2000@126.com

E-mail:xybxx@ccmu.edu.cn

Key words: multiple myeloma, cyclopamine, circularly permuted tumor necrosis factor related apoptosis inducing ligand, apoptosis have improved the outcome of patients with MM; however, almost all patients with MM relapse and become resistant to drugs $(3,4)$. Thus, it is of great importance to develop novel drugs that can overcome resistance. Tumor necrosis factor-related apoptosis-inducing ligand (TRAIL) is a member of the TNF superfamily and can specifically induce apoptosis of myeloma cells. Furthermore, it has no cytotoxic effects on hematopoietic stem cells and normal tissue cells (5). Beijing Sunbio Biotech Co., Ltd. has developed a recombinant version of TRAIL termed circularly permuted TRAIL (CPT). It has been shown that CPT exhibits potent antitumor activity in vivo and in vitro, but no effects on normal human cells (6). Compared with wild-type TRAIL, CPT exhibits improved stability and antitumor activity without significant toxic effects. CPT is a novel anti-myeloma drug prototype which has entered phase III clinical trials. In the previous phase II trials, CPT was shown to be effective as a treatment for MM, but there were some patients who exhibited resistance to CPT $(7,8)$. Thus, there is an urgent need to find novel drugs that can improve sensitivity of myeloma cells to CPT. Cyclopamine is the major Hedgehog signal pathway inhibitor and can induce apoptosis in certain types of cancer cells. Studies have shown that it exhibits synergistic therapeutic effects when combined with other anticancer drugs (9-12).

In the present study, two myeloma cell lines, RPMI-8266 and SKO-007, were used to evaluate the synergistic effects of cyclopamine and CPT on the proliferation and apoptosis of MM cells. It was shown that SKO-007 cells were resistant to both cyclopamine and CPT. However, the combination of cyclopamine and CPT exhibited a synergistic effect of inhibition of proliferation and induction of apoptosis in myeloma cells.

\section{Materials and methods}

Cells and reagents. The human myeloma cell lines RPMI-8226 and SKO-007 were obtained from Beijing Sunbio Biotech, Co., Ltd, and cultured in RPMI-1640 medium (Gibco; Thermo Fisher Scientific, Inc.) supplemented with 10\% FBS (Gibco; Thermo Fisher Scientific, Inc.), glutamine (2 mmol/l), penicillin $(100 \mathrm{IU} / \mathrm{ml})$ and streptomycin $(100 \mathrm{Ag} / \mathrm{ml})$, in a cell incubator containing $5 \% \mathrm{CO}_{2}$ at $37^{\circ} \mathrm{C}$. CPT was obtained from Beijing Sunbio Biotech, Co., Ltd., cyclopamine was purchased from Selleck Chemicals and the Cell Counting Kit-8 (CCK-8) assay kit was purchased from Sigma-Aldrich; Merck KGaA. 
An Annexin V-FITC apoptosis detection kit, Hoechst 33342 and verapamil were purchased from Sigma-Aldrich; Merck KGaA. Propidium iodide (PI) was purchased from BD Biosciences. Other reagents were purchased from Beijing Chemical Reagents Company, unless otherwise stated.

Cell growth inhibition assay. To determine the effects of cyclopamine and CPT on the proliferation of myeloma cells, cells ( $2 \times 10^{4}$ cells/well) in the logarithmic growth phase were seeded in a 96-well microtiter plate in a total volume of $100 \mu \mathrm{l}$. Cells were incubated in an incubator at $37^{\circ} \mathrm{C}$ with $5 \% \mathrm{CO}_{2}$ for $24 \mathrm{~h}$. The following day, medium containing increasing concentrations of cyclopamine and CPT were added. At different time intervals, the cell viability was measured using a CCK-8 kit assay according to the manufacturer's protocol. The proliferation inhibition rate was calculated using the following formula: Inhibition rate $(\%)=\mathrm{A} 490(\mathrm{drug}) / \mathrm{A} 490(\mathrm{control}) \times 100 \%$.

Assessment of apoptosis. Cells in the logarithmic growth phase were trypsinized and a cell suspension of $1 \times 10^{5}$ cells $/ \mathrm{ml}$ was prepared. The combination of $10 \mu \mathrm{mol} / 1$ cyclopamine combined and $100 \mathrm{ng} / \mathrm{ml} \mathrm{CPT}$ was selected because the maximum concentration of cyclopamine that we can get was $10 \mu \mathrm{mol} / 1$ and $100 \mathrm{ng} / \mathrm{ml} \mathrm{CPT}$ had a better inhibition effect at lower concentration. Different treatment times for the two drugs were selected because cyclopamine had relatively weak anti-myeloma effect and need more time to induce apoptosis compared to CPT according to the growth inhibition assay results. A total of $1 \times 10^{5}$ cells were seeded in 6 -well plates in a total volume of $3 \mathrm{ml}$ and incubated for $24 \mathrm{~h}$. The following day, media containing $10 \mu \mathrm{mol} / 1$ cyclopamine was added for $24 \mathrm{~h}$, and then media containing $100 \mathrm{ng} / \mathrm{ml} \mathrm{CPT}$ was added for $96 \mathrm{~h}$. All cells were harvested and cell apoptosis was determined using flow cytometry following Annexin V-FITC and PI staining, which was performed according to the manufacturer's protocols. The percent-specific cell apoptosis was calculated as follows: Non-apoptotic cells, Annexin V-negative and PI-negative; early apoptotic cells, Annexin V-positive and PI-negative; and necrotic cells or late apoptotic cells, Annexin V-positive and PI-positive.

Side population (SP) analysis. Cells in the logarithmic growth phase were trypsinized to prepare a suspension of cells $\left(1 \times 10^{5} / \mathrm{ml}\right)$. The cells were treated with CPT for $48 \mathrm{~h}$, since the SP cell ratio had more significant changes at this time point according to previous result. Cells were seeded in 6 -well plates in a total volume of $3 \mathrm{ml}$ media and incubated in a $5 \% \mathrm{CO}_{2}$ incubator at $37^{\circ} \mathrm{C}$ for $24 \mathrm{~h}$. The following day, medium containing $10 \mu \mathrm{mol} / 1$ cyclopamine was added and cells were incubated for a further $72 \mathrm{~h}$, and then medium containing $100 \mathrm{ng} / \mathrm{ml} \mathrm{CPT}$ was added for $48 \mathrm{~h}$. Subsequently, all cells were harvested and washed with PBS, and suspended at a density of $1 \times 10^{6}$ cells $/ \mathrm{ml}$ in culture medium containing 2\% FBS. SKO-007 cells were incubated with Hoechst 33342 dye at a final concentration of $5 \mu \mathrm{g} / \mathrm{ml}$ with or without verapamil $\left(100 \mu \mathrm{mol} / 1\right.$; ) at $37^{\circ} \mathrm{C}$ for $90 \mathrm{~min}$ with intermittent shaking every $15 \mathrm{~min}$. Cells preincubated with $100 \mu \mathrm{mol} / 1$ verapamil were used as the control group. PI $(2 \mu \mathrm{g} / \mathrm{ml})$ was added to label and exclude dead cells. SP cells that were not stained using Hoechst 33342 were counted using BD FACSAria SORP cytometer (BD Biosciences) and the data were analyzed with BD FACSDiva v.8.0.1 software (BD Biosciences).

Gene expression analysis. Cells in the logarithmic growth phase were trypsinized to prepare a cell suspension $\left(1 \times 10^{5}\right.$ cells $\left./ \mathrm{ml}\right)$. Cells were seeded in 6-well plates in a total volume of $3 \mathrm{ml}$ media and incubated in a $5 \% \mathrm{CO}_{2}$ incubator at $37^{\circ} \mathrm{C}$ for $24 \mathrm{~h}$. The following day, medium containing $10 \mu \mathrm{mol} / \mathrm{l}$ cyclopamine was added for $48 \mathrm{~h}$, and then medium containing $100 \mathrm{ng} / \mathrm{ml} \mathrm{CPT}$ was added for $24 \mathrm{~h}$. All cells were harvested, and TRIzol ${ }^{\circledR}$ (Invitrogen; Thermo Fisher Scientific Inc.) was used to isolate total RNA. A total amount of $2 \mu \mathrm{g} \mathrm{RNA}$ per sample was used for cDNA synthesis with a WCGENE ${ }^{\circledR}$ miRNA cDNA kit according to the manufacturer's protocol (Wcgene Biotech, Co., Ltd.). The gene expression levels of the genes of interest were quantified using WCGENE ${ }^{\circledR}$ miRNA qPCR mix (Wcgene Biotech, Co., Ltd.) according to the manufacturer's protocol. The sequences of the primers used in the PCR array analysis are listed in Table SI. $\beta$-actin and GAPDH were used as the endogenous loading controls. The relative gene expression levels of target genes were calculated using the $2^{-\Delta \Delta \mathrm{Cq}}$ method (13).

Statistical analysis. Data are presented as the mean \pm standard deviation of three repeats. Statistical analysis was performed using a one-way ANOVA test with post hoc contrasts by SNK test. Jin's formula: $\mathrm{q}=\mathrm{Ea}+\mathrm{Eb} /(\mathrm{Ea}+\mathrm{Eb}-\mathrm{Ea} \mathrm{x} \mathrm{Eb})$, was used to evaluate whether two drugs had a synergistic effect. $\mathrm{Ea}+\mathrm{Eb}$ represents the inhibition ratio of the combination group and $\mathrm{Ea}$ and $\mathrm{Eb}$ represented respectively the inhibition ratios of simple drug a and simple group $b$. If the calculated $q$ value was between 0.85 and 1.15 , the effect of combination of two drugs was the simple summation of respective effects; however, if $q>1.15$, the two drugs had a synergistic effect; whereas if $\mathrm{q}<0.85$, the two drugs had an antagonistic effect. $\mathrm{P}<0.05$ was considered to indicate a statistically significant difference.

\section{Results}

Cyclopamine enhances CPT-induced decrease in the proliferation of MM cells. Following treatment with cyclopamine, the proliferation of RPMI-8226 cells was weakly decreased. At lower doses, the inhibition of proliferation was very low and high doses of cyclopamine increased inhibition. The maximum concentration of cyclopamine that could be prepared was $10 \mu \mathrm{mol} / \mathrm{l}$. The inhibition rate of $10 \mu \mathrm{mol} / \mathrm{l}$ cyclopamine was significantly higher compared with that of $5 \mathrm{nmol} / \mathrm{l}$ cyclopamine $(\mathrm{P}<0.01)$, when treated for the same amount of time. However, there were no significant differences between treatment with concentrations $\leq 1 \mu \mathrm{mol} / 1$ $(\mathrm{P}>0.05)$. The inhibition rate was $<40 \%$, when treated with a very high concentration of cyclopamine, which was close to the maximum concentration, thus, it was hypothesized that RPMI-8226 cells were resistant to cyclopamine (Table I). Similarly, the inhibitory effect of cyclopamine on SKO-007 cells was also weak. The inhibitory rate of $10 \mu \mathrm{M}$ cyclopamine was also significantly higher compared with that of $5 \mathrm{nmol} / \mathrm{l}$ cyclopamine $(\mathrm{P}<0.05)$. The maximum inhibitory rate was $<40 \%$, and SKO-007 cells were also resistant to cyclopamine (Table I). 
Table I. Inhibitory effects of cyclopamine on RPMI-8226 and SKO-007 cell proliferation.

A, RPMI-8226 cell proliferation inhibition rate, $\%$

\begin{tabular}{lccccc}
\hline & \multicolumn{5}{c}{ Cyclopamine, nmol/l } \\
\cline { 2 - 6 } Treatment times, h & 5 & 20 & 100 & 1,000 & 10,000 \\
\hline 24 & $3.00 \pm 7.11$ & $-2.39 \pm 7.27$ & $2.70 \pm 4.41$ & $5.53 \pm 5.03$ & $12.39 \pm 4.55^{\mathrm{b}}$ \\
72 & $-2.36 \pm 11.80$ & $-0.16 \pm 18.86$ & $10.39 \pm 17.99$ & $7.09 \pm 11.20$ & $20.71 \pm 7.01^{\mathrm{b}}$ \\
120 & $2.12 \pm 17.02$ & $8.12 \pm 17.31$ & $10.43 \pm 7.53^{\mathrm{a}}$ & $4.53 \pm 17.06$ & $34.52 \pm 12.09^{\mathrm{b}}$ \\
\hline
\end{tabular}

$\mathrm{B}, \mathrm{SKO}-007$ cell proliferation inhibition rate, $\%$

\begin{tabular}{lccccc}
\hline & \multicolumn{5}{c}{ Cyclopamine, nmol/1 } \\
\cline { 2 - 6 } Treatment times, h & 5 & 20 & 100 & 1,000 & 10,000 \\
\hline 24 & $1.96 \pm 6.85$ & $-2.27 \pm 7.17$ & $2.80 \pm 3.65$ & $3.46 \pm 4.89$ & $5.00 \pm 3.19^{\mathrm{a}}$ \\
72 & $-6.77 \pm 9.25$ & $-5.32 \pm 16.78$ & $2.40 \pm 14.79$ & $5.53 \pm 11.50$ & $18.86 \pm 5.89^{\mathrm{a}}$ \\
120 & $0.36 \pm 17.39$ & $6.34 \pm 17.94$ & $6.68 \pm 11.55$ & $7.96 \pm 18.97$ & $36.67 \pm 8.40^{\mathrm{b}}$ \\
\hline
\end{tabular}

${ }^{a} \mathrm{P}<0.05 \mathrm{vs} .0 \mathrm{nmol} / \mathrm{l} ;{ }^{\mathrm{b}} \mathrm{P}<0.05$ vs. $0 \mathrm{nmol} / \mathrm{l}$. TRAIL, tumor necrosis factor related apoptosis inducing ligand; CPT, circularly permuted TRAIL.

CPT significantly inhibited the proliferation of RPMI8226 cells in both a time- and dose-dependent manner $(\mathrm{P}<0.05)$. After $72 \mathrm{~h}$ of treatment, the inhibitory rate of treatment with a low dose was $>50 \%$, and $~ 80 \%$. with a high dose. Therefore, RPMI-8226 cells were sensitive to CPT. However, the proliferation of SKO-007 cells was not effectively inhibited by CPT. When treated with $10 \mu \mathrm{g} / \mathrm{ml} \mathrm{CPT}$, the inhibitory rate was $20.49 \pm 3.4 \%, 29.82 \pm 13.07 \%$ and $11.68 \pm 23.26 \%$ at 24,72 and $120 \mathrm{~h}$ post-treatment, respectively. The inhibitory rate was $<30 \%$ when treated with a very high concentration, thus SKO-007 cells were considered resistant to CPT (Table II).

To determine whether cyclopamine can increase the sensitivity of myeloma cells to CPT, SKO-007 cells were selected for subsequent experiments, since they were considered as resistant to cyclopamine and CPT. The effects of a combination of cyclopamine and CPT on the proliferation of SKO-007 cells were evaluated using $10 \mu \mathrm{mol} / \mathrm{l}$ cyclopamine, and 10 and $100 \mathrm{ng} / \mathrm{ml} \mathrm{CPT}$ after 96 and $120 \mathrm{~h}$ post-treatment. This showed that a combination of cyclopamine and CPT could significantly inhibit cell proliferation, and the inhibitory rate of 10 and $100 \mathrm{ng} / \mathrm{ml} \mathrm{CPT} \mathrm{combined} \mathrm{with} 10 \mu \mathrm{mol} / 1$ cyclopamine was $19.65 \pm 13.71 \%$ and $35.82 \pm 10.91 \% 96 \mathrm{~h}$ post-treatment, respectively $(\mathrm{P}<0.05)$. Moreover, the $\mathrm{Q}$ value showed that cyclopamine combined with CPT could synergistically inhibit the proliferation of SKO-007 cells (1.40 and 2.55, respectively). A total of $120 \mathrm{~h}$ post-treatment, the inhibitory rate of 10 and $100 \mathrm{ng} / \mathrm{ml} \mathrm{CPT} \mathrm{combined} \mathrm{with} 10 \mu \mathrm{mol} / 1$ cyclopamine was $53.80 \pm 7.85 \%$ and $62.62 \pm 5.08 \%$, respectively $(\mathrm{P}<0.05)$ and also showed synergistic inhibition on proliferation (Q value, 1.57 and 2.09, respectively; Table III).

Cyclopamine promotes CPT-induced apoptosis in resistant SKO-007 cells. Annexin V and PI double staining and flow cytometry were used to measure the induction of apoptosis by cyclopamine $(10 \mu \mathrm{mol} / \mathrm{l})$ and CPT $(100 \mathrm{ng} / \mathrm{ml})$ in SKO-007 cells. The percentage of cells that were considered as early apoptotic when treated with cyclopamine and CPT was $6.59 \pm 0.71 \%$ and $12.13 \pm 0.85 \%$, respectively. Combination of cyclopamine and CPT increased the proportion of apoptotic cells $(41.48 \pm 3.58 \%)$. Compared with the control cells $(5.38 \pm 1.08 \%)$, cyclopamine and CPT were able to increase the proportion of apoptotic cells $(\mathrm{P}<0.05)$ and the combination of the two drugs had a synergistic effect on induction of apoptosis (Q value, 2.31; Fig. 1 and Table SII).

Cyclopamine combined with CPT effectively decreases the proportion of SP cells. The proportion of SP cells was very low in SKO-007 cells; the percentage of SP cells was $1.79 \pm 0.08 \%$ in untreated cells. The percentage of SP cells when treated with cyclopamine or CPT were $0.74 \pm 0.12 \%$ and $0.96 \pm 0.20 \%$, respectively. Treatment with a combination of cyclopamine and CPT decreased the proportion of SP cells $(0.20 \pm 0.11 \%)$. Compared with the control cells, cyclopamine and CPT were able to further decrease the proportion of SP cells $(\mathrm{P}<0.05$; Fig. 2 and Table SIII).

Cyclopamine sensitizes SKO-007 cells to CPT through upregulation of DR4 expression. Results of qPCR analysis showed that cyclopamine decreased the expression levels of GLI1/GLI2/GLI3; however, the expression levels of other genes involved in the Hedgehog signaling pathway were not significantly altered. The mRNA expression levels of genes involved in the Hedgehog signaling pathway were not notably altered following treatment with CPT. The expression levels of GLI1/GLI2/GLI3 decreased and those of SHH and DHH increased when SKO-007 cells were treated with cyclopamine combined with CPT. Following treatment with cyclopamine, the expression levels of DR4 and FasL increased and those of 
Table II. Inhibitory effects of CPT on RPMI-8226 and SKO-007 cells proliferation.

A, RPMI-8226 cell proliferation inhibitory effect, $\%$

\begin{tabular}{lcccccc}
\hline & \multicolumn{5}{c}{ CPT, ng/ml } \\
\cline { 2 - 6 } Treatment times, $\mathrm{h}$ & 5 & 20 & 100 & 500 & 2,000 \\
\hline 24 & $6.06 \pm 5.49$ & $13.22 \pm 5.49^{\mathrm{a}}$ & $25.70 \pm 4.50^{\mathrm{b}}$ & $33.49 \pm 9.32^{\mathrm{b}}$ & $/$ & 10,000 \\
48 & $11.73 \pm 7.11$ & $32.29 \pm 8.18^{\mathrm{b}}$ & $44.89 \pm 8.91^{\mathrm{b}}$ & $50.47 \pm 6.45^{\mathrm{b}}$ & $/$ & $/$ \\
72 & $29.32 \pm 7.22^{\mathrm{b}}$ & $54.91 \pm 7.19^{\mathrm{b}}$ & $71.70 \pm 7.66^{\mathrm{b}}$ & $78.44 \pm 3.00^{\mathrm{b}}$ & $/$ & $/$ \\
\hline
\end{tabular}

B, SKO-007 cell proliferation inhibitory effect, $\%$

\begin{tabular}{lcccccc}
\hline & \multicolumn{5}{c}{ CPT, ng/ml } \\
\cline { 2 - 7 } Treatment times, h & 5 & 20 & 100 & 500 & 2,000 & 10,000 \\
\hline 24 & $12.05 \pm 6.53$ & $4.77 \pm 9.63$ & $3.01 \pm 3.20$ & $7.85 \pm 5.70$ & $15.39 \pm 7.79^{\mathrm{b}}$ & $20.49 \pm 3.74^{\mathrm{b}}$ \\
72 & $17.75 \pm 21.25$ & $18.58 \pm 21.46$ & $20.68 \pm 18.12$ & $19.14 \pm 13.57$ & $27.00 \pm 17.83^{\mathrm{a}}$ & $29.82 \pm 13.07^{\mathrm{a}}$ \\
120 & $-2.50 \pm 14.24$ & $-7.48 \pm 14.57$ & $-2.39 \pm 12.50$ & $3.88 \pm 19.28$ & $10.05 \pm 22.50$ & $11.68 \pm 23.26$ \\
\hline
\end{tabular}

${ }^{\mathrm{a}} \mathrm{P}<0.05$ vs. $0 \mathrm{nmol} / \mathrm{l} ;{ }^{\mathrm{b}} \mathrm{P}<0.05$ vs. $0 \mathrm{nmol} / \mathrm{l}$.

Table III. Combination effects of cyclopamine and CPT on SKO-007 cells proliferation.

\begin{tabular}{|c|c|c|c|c|}
\hline Treatment times, $\mathrm{h}$ & Cyclopamine, $\mu \mathrm{mol} / 1$ & CPT, ng/ml & Inhibitory rate, $\%$ & Q-value \\
\hline \multirow[t]{5}{*}{96} & 10 & 0 & $11.67 \pm 13.67$ & \\
\hline & 0 & 10 & $2.66 \pm 10.26$ & \\
\hline & 0 & 100 & $2.72 \pm 16.00$ & \\
\hline & 10 & 10 & $19.65 \pm 13.71^{\mathrm{a}, \mathrm{c}}$ & 1.40 \\
\hline & 10 & 100 & $35.82 \pm 10.91^{\mathrm{a}-\mathrm{d}}$ & 2.55 \\
\hline \multirow[t]{5}{*}{120} & 10 & 0 & $28.91 \pm 15.20^{\mathrm{a}, \mathrm{b}}$ & \\
\hline & 0 & 10 & $7.41 \pm 9.08^{b}$ & \\
\hline & 0 & 100 & $1.41 \pm 7.35^{\mathrm{b}}$ & \\
\hline & 10 & 10 & $53.80 \pm 7.85^{\mathrm{a}-\mathrm{d}}$ & 1.57 \\
\hline & 10 & 100 & $62.62 \pm 5.08^{\mathrm{a}-\mathrm{e}}$ & 2.09 \\
\hline
\end{tabular}

${ }^{\mathrm{a}} \mathrm{P}<0.05$ vs. $0 \mathrm{nmol} / \mathrm{l}$ drugs; ${ }^{\mathrm{b}} \mathrm{P}<0.05$ vs. $10,000 \mathrm{nmol} / \mathrm{l}$ cyclopamine; ${ }^{\mathrm{c}} \mathrm{P}<0.05 \mathrm{vs} .10 \mathrm{ng} / \mathrm{ml}$; ${ }^{\mathrm{d}} \mathrm{P}<0.05 \mathrm{vs} .100 \mathrm{ng} / \mathrm{ml} \mathrm{CPT} ;{ }^{\mathrm{e}} \mathrm{P}<0.05 \mathrm{vs}$. combination of $10,000 \mathrm{nmol} / \mathrm{l}$ cyclopamine and $10 \mathrm{ng} / \mathrm{ml} \mathrm{CPT}$.

other genes involved in TRAIL-induced signaling pathways were not changed. The expression levels of FasL further increased when SKO-007 cells were treated with cyclopamine combined with CPT. However, there was no significant effect of CPT treatment alone on the expression levels of TRAIL signaling pathway genes. In the mitochondrial pathway of apoptosis, the expression levels of Noxa were increased in SKO-007 cells treated with drugs, whereas expression of other genes involved in this pathway were not notably altered (Fig. 3 and Table SIV).

\section{Discussion}

TRAIL is a member of the tumor necrosis factor super family, and exhibits antitumor, anti-virus and immunoregulatory effects. There are five interacting partners: Death receptor 4 (DR4), DR5, decoy receptor 1 (DcR1), DcR2 and osteoprotegerin, and TRAIL binds to the extracellular domain of these receptors. TRAIL can induce cell apoptosis by activating apoptosis signaling pathways when it binds with DR4 and DR5. However, extracellular domains of the other three receptors are short and cannot activate apoptotic signaling $(14,15)$. TRAIL receptor expression levels are different in normal tissues and tumor tissues. Major tumor cells express death receptors but not DcR1 and DcR2; however, normal cells express death receptors and decoy receptors. DcR1 and DcR2 cannot induce apoptosis; moreover, these two receptors may inhibit apoptosis induced by DR4 and DR5. Thus, TRAIL can induce apoptosis of tumor cells and has no harmful effects on normal cells (16). Therefore, TRAIL may serve as a promising novel candidate drug for the 

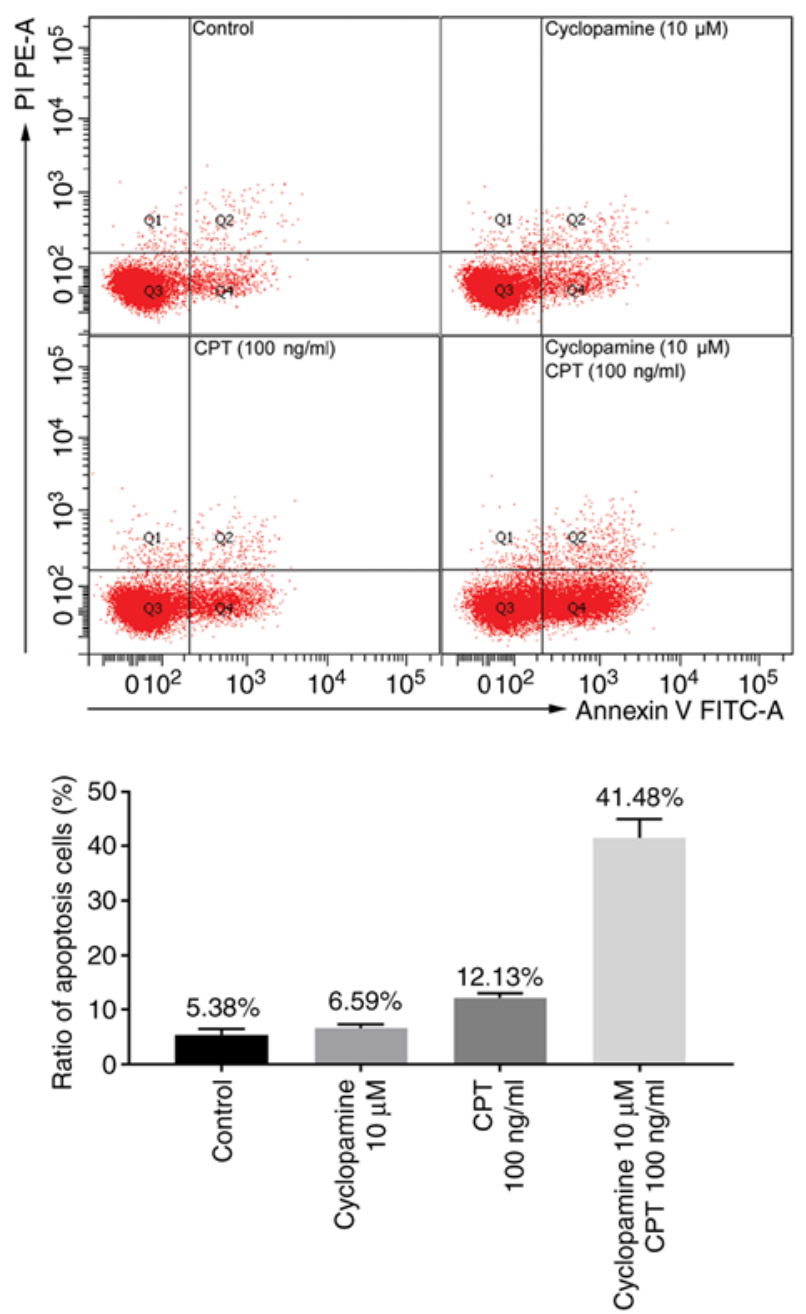

Figure 1. Effects of cyclopamine and CPT on the apoptosis of SKO-007 cells. TRAIL, tumor necrosis factor related apoptosis inducing ligand; CPT, circularly permuted TRAIL; PI, propidium iodide.

treatment of MM $(17,18)$. However, none of the clinical trials utilizing TRAIL and the antibodies against death receptors have exhibited objective clinical benefits. Thus, recombinant gene technology has been used to create analogues that exhibit enhanced function compared with physiological TRAIL on tumor cells. To improve its activity, the TRAIL protein was mutated to form CPT (6). Compared with wild-type TRAIL, CPT exhibits excellent water solubility, higher bioactivity and enhanced stability. In the phase 2 study of 71 patients with relapsed or refractory MM, 47 patients were assigned to the CPT + thalidomide and dexamethasone (TD) group, and 24 patients were recruited to the TD group. The overall response rate in the $\mathrm{CPT}+\mathrm{TD}$ group was 38.3 vs. $25.0 \%$ in the TD group. The median progression free survival time was 6.7 months for the CPT + TD group and 3.1 months for the TD group. The median duration of response for the CPT + TD and TD groups were 7.1 and 3.2 months, respectively (19). Other studies also showed that CPT was effective against MM, but there were some patients who were resistant to CPT $(7,8)$. It is suggested that tumor cells may survive CPT treatment though inactivation of signaling pathways induced by TRAIL.

In myeloma cells, there is a rare subpopulation of cells that possess the capacity for self-renewal and drug resistance
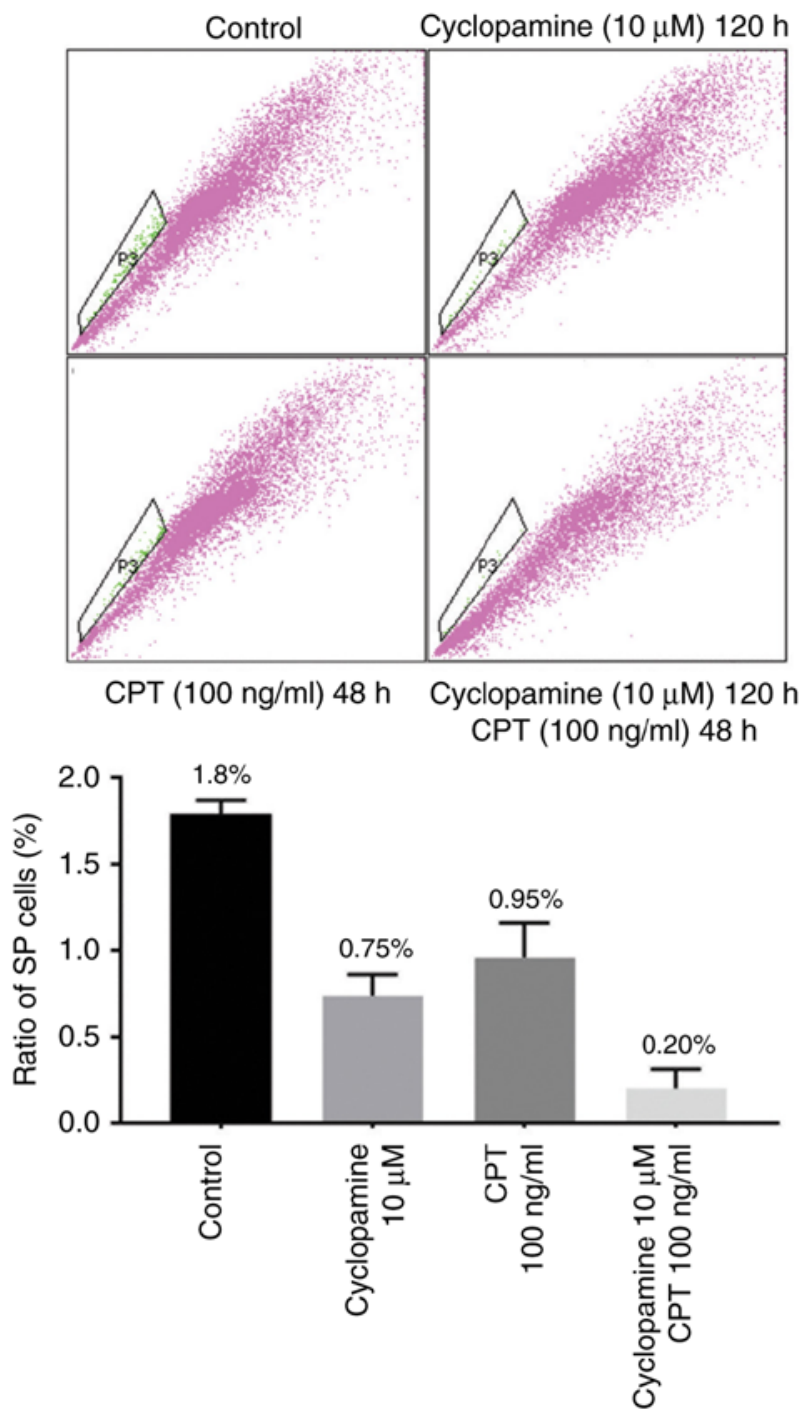

Figure 2. Effects of cyclopamine and CPT on SP cells in SKO-007 cells. TRAIL, tumor necrosis factor related apoptosis inducing ligand; CPT, circularly permuted TRAIL; SP, side population.

and these cells are termed myeloma stem cells (MSCs) which are considered to underlie drug resistance (20). Treatments targeting MSCs are effective in inhibiting the proliferation of myeloma cells $(21,22)$. The Hedgehog signaling pathway is one of the major signaling pathways involved in the regulation of self-renewal and differentiation of MSCs. Targeting this pathway may improve the efficacy of chemotherapy in patients with MM (23). Cyclopamine is the first small molecule Hedgehog signaling pathway inhibitor that directly targets the transmembrane receptor Smoothened. Cyclopamine can induce apoptosis in certain types of cancer cells and exhibits synergistic therapeutic effects when combined with other anti-cancer drugs (9-12). In order to determine whether cyclopamine can enhance the sensitivity of CPT to myeloma cells, the effects of cyclopamine and CPT on myeloma cells were assessed.

In the present study, the inhibitory effect of cyclopamine on the proliferation of RPMI-8226 and SKO-007 cells was weak. The inhibitory rate was $<40 \%$ when a very high concentration was used, which was close to the maximum concentration. 

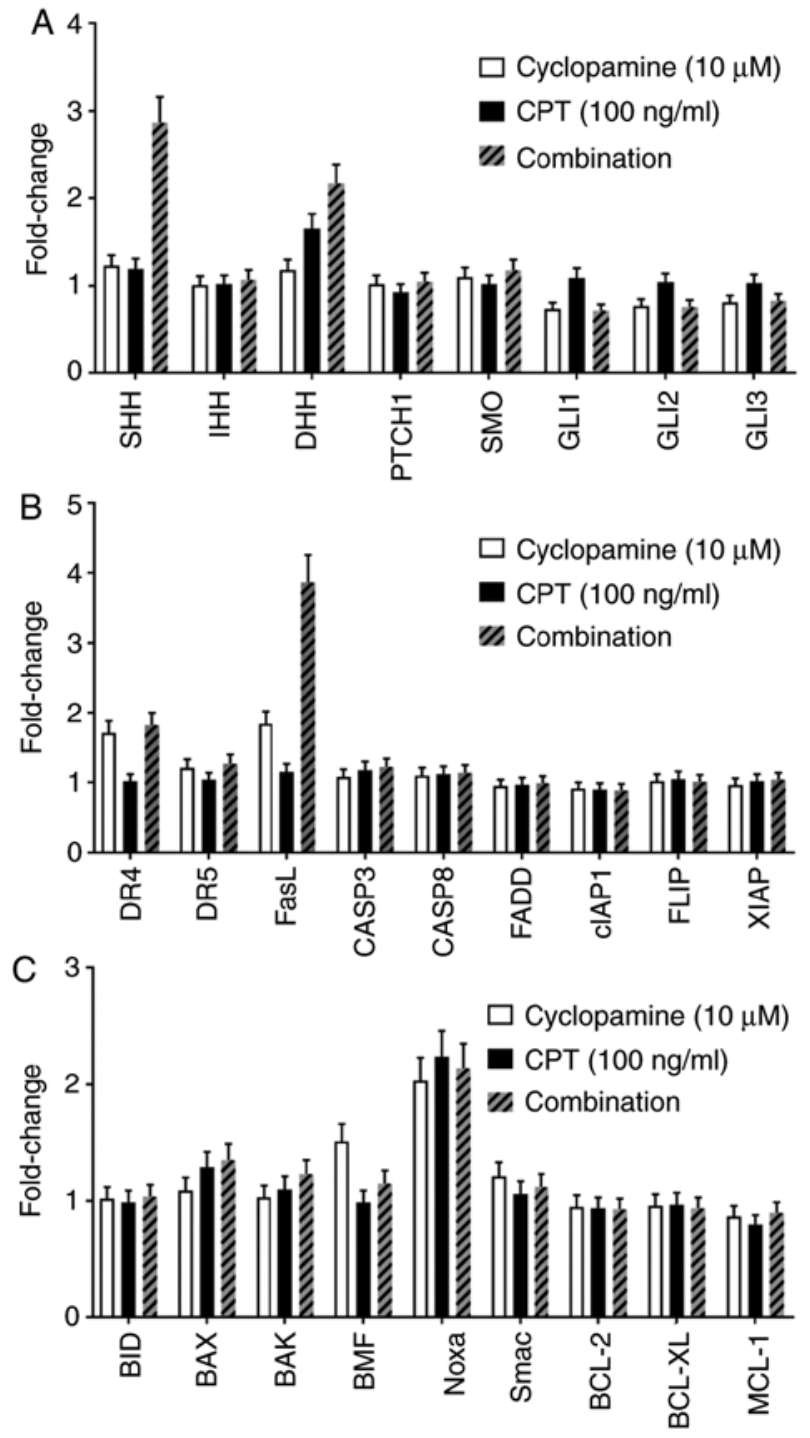

Figure 3. Effects of cyclopamine and CPT on gene expression in SKO-007 cells. (A) Expression of genes of Hedgehog signal pathway. (B) Expression of genes of TRAIL signal pathway. (C) Expression of genes of mitochondrial pathway. TRAIL, tumor necrosis factor related apoptosis inducing ligand; CPT, circularly permuted TRAIL.

therefore, the $50 \%$ inhibiting concentration $\left(\mathrm{IC}_{50}\right)$ values were not calculated. Thus, RPMI-8226 and SKO-007 cells were considered resistant to cyclopamine. As described in a previous study, RPMI-8226 cells were sensitive to CPT (24). The inhibitory rate of low-dose treatment was $>50 \%$ and that of the high dose was $\sim 80 \%$. However, the proliferation of SKO-007 cells was not effectively inhibited by CPT. The inhibitory rate was $<30 \%$ when a very high concentration was used, thus, SKO-007 cells were considered resistant to CPT. To determine whether cyclopamine increased the sensitivity of myeloma cells to CPT, SKO-007 cells, which were resistant to cyclopamine and CPT, were used for subsequent experiments. The results showed that a combination of cyclopamine and CPT could significantly decrease cell proliferation. Moreover, the Q value showed that cyclopamine combined with CPT could synergistically inhibit the proliferation of SKO-007 cells.

It was shown that cyclopamine induced apoptosis in SKO-007 cells; however, these cells were not sensitive to cyclopamine. Similarly, SKO-007 cells were also resistant to apoptosis induced by CPT. Cyclopamine could enhance induction of CPT on SKO-007 cells and induction of apoptosis when combined. Moreover, cyclopamine and CPT exhibited notable effects on the SP cells, which were representative of MSCs. SP cells are rare in SKO-007 cells and the proportion of these cells was decreased following treatment with drugs. Combinations of these two drugs significantly killed SP cells. This suggests that the combination of cyclopamine and CPT may be able to eliminate MSCs, the root of MM relapse.

The results of the present study showed that cyclopamine was able to decrease the mRNA expression levels of GLI1/GLI2/GLI3, all of which are involved in the Hedgehog signaling pathway. The expression of $\mathrm{SHH}$ and $\mathrm{DHH}$ was increased when SKO-007 cells were treated with cyclopamine combined with CPT. It is suggested that cyclopamine is an effective inhibitor of the Hedgehog signaling pathway and the increased expression of SHH and DHH may serve as feedback adjustment to low expression levels of the downstream genes. The expression levels of DR4 are increased in SKO-007 cells treated with cyclopamine. It was hypothesized that the inhibition of the hedgehog signaling pathway may influence the expression of TRAIL signaling pathway genes and increase DR4 expression. High levels of DR4 improve TRAIL signaling pathway activity and increases CPT-induced apoptosis in SKO-007 cells. Thus, cyclopamine enhanced the sensitivity of SKO-007 cells to CPT. In addition, expression level changes of upstream genes in apoptosis signaling pathways may be induced via a cascade reaction of downstream genes and altered expression levels of associated genes. Further experiments may better reveal the mechanisms underlying the synergistic effects.

In summary, the present study demonstrated that SKO-007 cells were resistant to cyclopamine and CPT. These two drugs exhibit a synergistic effect on the inhibition of proliferation and the induction of apoptosis in SKO-007 cells. Moreover, the combinations of cyclopamine and CPT may inhibit MSCs, which are hypothesized to be the root of MM relapse. Cyclopamine may increase expression of DR4 and this may underlie the increased sensitivity of SKO-007 cells to CPT.

\section{Acknowledgements}

Not applicable.

\section{Funding}

This work was supported by the National Natural Science Foundation of China (Youth Program; grant no. 81500164).

\section{Availability of data and materials}

The analyzed data sets generated during the study are available from the corresponding author on reasonable request.

\section{Authors' contributions}

$\mathrm{HW}, \mathrm{HZ}$, and $\mathrm{ZZ}$ performed the experiments. $\mathrm{HW}$ and $\mathrm{CG}$ confirm the authenticity of all the raw data. CG and WC 
conceived and designed the study. CG wrote the manuscript. All authors read and approved the manuscript.

\section{Ethics approval and consent to participate}

Not applicable.

\section{Patient consent for publication}

Not applicable.

\section{Competing interests}

The authors declare that they have no competing interests.

\section{References}

1. Martin T and Huff CA: Multiple myeloma: Current advances and future directions. Clin Lymphoma Myeloma Leuk 19: 255-263, 2019.

2. Ziogas DC, Dimopoulos MA and Kastritis E: Prognostic factors for multiple myeloma in the era of novel therapies. Expert Rev Hematol 11: 863-879, 2018.

3. Ishida T: Therapeutic antibodies for multiple myeloma. Jpn J Clin Oncol 48: 957-963, 2018.

4. Aljama MA, Sidiqi MH and Dingli D: Therapy for relapsed multiple myeloma. Panminerva Med 60: 174-184, 2018.

5. Gazitt Y: TRAIL is a potent inducer of apoptosis in myeloma cells derived from multiple myeloma patients and is not cytotoxic to hematopoietic stem cells. Leukemia 13: 1817-1824, 1999.

6. Fang F, Wang AP and Yang SF: Antitumor activity of a novel recombinant mutant human tumor necrosis factor-related apoptosis-inducing ligand. Acta Pharmacol Sin 26: 1373-1381, 2005.

7. Geng C, Hou J, Zhao Y, Ke X, Wang Z, Qiu L, Xi H, Wang F, Wei N, Liu Y, et al: A multicenter, open-label phase II study of recombinant CPT (Circularly Permuted TRAIL) plus thalidomide in patients with relapsed and refractory multiple myeloma. Am J Hematol 89: 1037-1042, 2014

8. Leng Y, Qiu L, Hou J, Zhao Y, Zhang X, Yang S, Xi H, Huang Z, Pan L and Chen W: Phase II open-label study of recombinant circularly permuted TRAIL as a single-agent treatment for relapsed or refractory multiple myeloma. Chin J Cancer 35: 86, 2016.

9. Fan C, Wang Y, Liu Z, Sun Y, Wang X, Wei G and Wei J: Metformin exerts anticancer effects through the inhibition of the Sonic hedgehog signaling pathway in breast cancer. Int J Mol Med 36: 204-214, 2015.

10. Gonnissen A, Isebaert S and Haustermans K: Hedgehog signaling in prostate cancer and its therapeutic implication. Int J Mol Sci 14: 13979-14007, 2013.

11. Yang R, Mondal G, Wen D and Mahato RI: Combination therapy of paclitaxel and cyclopamine polymer-drug conjugates to treat advanced prostate cancer. Nanomedicine 13: 391-401, 2017.
12. Iovine V, Mori M, Calcaterra A, Berardozzi S and Botta B: One hundred faces of cyclopamine. Curr Pharm Des 22: 1658-1681, 2016.

13. Livak KJ and Schmittgen TD: Analysis of relative gene expression data using real-time quantitative PCR and the 2(-Delta Delta C(T)) method. Methods 25: 402-408, 2001.

14. Hassanzadeh A, Farshdousti Hagh M, Alivand MR, Akbari AAM, Shams Asenjan K, Saraei R and Solali S: Down-regulation of intracellular anti-apoptotic proteins, particularly c-FLIP by therapeutic agents; the novel view to overcome resistance to TRAIL. J Cell Physiol 233: 6470-6485, 2018.

15. Yuan X, Gajan A, Chu Q, Xiong H, Wu K and Wu GS: Developing TRAIL/TRAIL death receptor-based cancer therapies. Cancer Metastasis Rev 37: 733-748, 2018.

16. Testa U: TRAIL/TRAIL-R in hematologic malignancies. J Cell Biochem 110: 21-34, 2010.

17. Buckle $\mathrm{CH}$, Neville-Webbe HL, Croucher PI and Lawson MA: Targeting RANK/RANKL in the treatment of solid tumours and myeloma. Curr Pharm Des 16: 1272-1283, 2010.

18. Arhoma A, Chantry AD, Haywood-Small SL and Cross NA: SAHA-induced TRAIL-sensitisation of multiple myeloma cells is enhanced in 3D cell culture. Exp Cell Res 360: 226-235, 2017.

19. Leng Y, Hou J, Jin J, Zhang M, Ke X, Jiang B, Pan L, Yang L, Zhou F, Wang J, et al: Circularly permuted TRAIL plus thalidomide and dexamethasone versus thalidomide and dexamethasone for relapsed/refractory multiple myeloma: A phase 2 study. Cancer Chemother Pharmacol 79: 1141-1149, 2017.

20. Gao M, Kong Y, Yang G, Gao L and Shi J: Multiple myeloma cancer stem cells. Oncotarget 7: 35466-35477, 2016.

21. Shi F, Li M, Wang J, Wu D, Pan M, Guo M and Dou J: Induction of multiple myeloma cancer stem cell apoptosis using conjugated anti-ABCG2 antibody with epirubicin-loaded microbubbles. Stem Cell Res Ther 9: 144, 2018.

22. Shi F, Li M, Wu S, Yang F, Di W, Pan M, Zhao F, Luo S, Gu N and Dou J: Enhancing the anti-multiple myeloma efficiency in a cancer stem cell xenograft model by conjugating the ABCG2 antibody with microbubbles for a targeted delivery of ultrasound mediated epirubicin. Biochem Pharmacol 132: 18-28, 2017.

23. Liu Z, Xu J, He J, Zheng Y, Li H, Lu Y, Qian J, Lin P, Weber DM, Yang $J$ and Yi Q: A critical role of autocrine sonic hedgehog signaling in human CD138+ myeloma cell survival and drug resistance. Blood 124: 2061-2071, 2014

24. Wang J, Li Y, Sun W, Liu J and Chen W: Synergistic effects of rmhTRAIL and 17-AAG on the proliferation and apoptosis of multiple myeloma cells. Hematology 23: 620-625, 2018. 